\title{
Peranan Fisioterapi pada Kasus Hallux Valgus (Bunion) dengan Intervensi NMT dan Strengthening untuk Mengurangi Nyeri
}

\author{
Ismaningsih ${ }^{1)}$, Nova Relida Samosir ${ }^{2)}$, Maulidya ${ }^{3)}$ \\ 1,2,3) Program Studi D-III Fisioterapi Fakultas Farmasi dan Ilmu Kesehatan \\ Universitas Abdurrab \\ Jl. Riau Ujung no. 73 Pekanbaru \\ Email : ismaningsih@univrab.ac.id
}

\begin{abstract}
Background Hallux valgus (HV), also known as bunion is one of the most common foot deformities. It manifests with the proximal phalanx deviating laterally and the first metatarsal head deviating medially, usually due to adduction of the first metatarsus, called the metatarsus primus varus. The deformity is sometimes red in color and very painful to daily activities. If identified and treated properly the symptoms will improve. The exact etiology is not fully understood. It tends to occur more frequently in women and those who wear shoes or tight heels, hallux valgus is found in 58\% of women and $25 \%$ of men. HV deformities can usually be diagnosed by physical examination. This deformity is sometimes red in color and painfully interferes with daily activities. If identified and treated properly the symptoms will improve. The aim of this study was to determine the effect of neuromuscular taping intervention and strengthening exercise on pain reduction. The Research Method is a literature study consisting of sources -the research source used the final evaluation, namely the Visual Analogue Scale (VAS). The results in the literature study showed a reduction in pain after neuromuscular taping and strengthening exercises. From this literature study it can be concluded that the intervention of neuromuscular taping and strengthening exercise is effective in reducing pain., increases the strength of M. Abductor hallucis muscles as well as reduces the hallux valgus angle.
\end{abstract}

Keywords : Hallux Valgus,Neuromuskular Taping,Strengthening Exercise.

\section{ABSTRAK}

Latar Belakang: Hallux valgus (HV),juga dikenal sebagai bunion adalah salah satu kelainan bentuk kaki yang paling umum.ini bermanifestasi dengan phalanx proksimal menyimpang ke lateral dan kepala metatarsal pertama menyimpang ke medial,biasanya karena adduksi metatarsus pertama,yang disebut metatarsus primus varus. Kelainan bentuk ini terkadang berwarna merah dan nyeri sangat menganggu aktivitas sehari-hari.jika diidentifikasi dan diobati dengan benar gejalanya akan membaik.etiologi tepatnya tidak sepenuhnya dipahami. Ini cenderung terjadi lebih sering pada wanita dan mereka yang memakai sepatu atau tumit ketat,hallux valgus ditemukan pada $58 \%$ wanita dan $25 \%$ pria.deformitas $\mathrm{HV}$ biasanya dapat didiagnosis melalui pemeriksaan fisik. Kelainan bentuk ini terkadang berwarna merah dan nyeri sangat menganggu aktivitas sehari-hari.jika diidentifikasi dan diobati dengan benar gejalanya akan membaik. Tujuan penelitian ini untuk mengetahui pengaruh intervensi neuromuscular taping dan strengthening exercise terhadap penurunan nyeri. Metode Penelitian adalah studi literature yang terdiri dari sumber-sumber penelitian dengan menggunakan evaluasi akhir yaitu Visual Analogue Scale (VAS). Hasil pada Studi literature menunjukkan adanya penurunan nyeri sesudah dilakukannya tindakan neuromuscular taping dan strengthening exercise.Dari penelitian studi literature ini dapat disimpulkan bahwa intervensi neuromuscular taping dan strengthening exercise efektif dalam mengurangi nyeri,meningkatkan kekuatan otot M.Abductor hallucis serta mengurangi sudut hallux valgus.

Kata kunci : Hallux Valgus,Neuromuskular Taping,Strengthening Exercise. 


\section{Pendahuluan}

Hallux Valgus atau Bunion adalah pembengkokan ibu jari kaki menuju lateral atau menuju jari-jari kaki lainnya pada sisi medial capitulum metatarsi pertama disertai pembentukan bursa atau kantong yang berisi cairan yang dapat menyebabkan pergeseran ibu jari kaki (1).

Hallux Valgus atau Bunion merupakan penyakit progresif. Timbulnya nyeri atau rasa kaku akibat penebalan kulit ditempat yang mengalami tekanan berlebih, tonjolan pada sendi Metatarsophalangeal pertama, jika sudah mengalami komplikasi berupa bursitis akan muncul tanda inflamasi seperti kemerahan, kesulitan menggerakkan atau berjalan merupakan suatu gejala terjadinya Hallux Valgus atau bunion. Tidak semua penderita Hallux Valgus atau bunion akan mengalami gejala, deteksi Hallux Valgus atau bunion sebaiknya dilakukan sedini mungkin untuk mencegah semakin memburuknya progresivitas penyakit dan dapat menyebabkan penurunan produktivitas. (2)

\section{Tinjauan Pustaka}

\subsection{Nyeri pada Hallux Valgus}

Hallux valgus merupakan kondisi yang umum dialami, namun banyak yang tidak menyadarinya dikarenakan belum ada gejala difase awal. Kasus ini merupakan penyakit multifaktorial, yaitu adanya faktor instrinsik dan ekstrinsik seperti berdiri lama dengan menggunakan alas kaki yang tidak sesuai. (3)

Hallux Valgus atau Bunion merupakan kelainan bentuk progresif yang complex bermanifestasi dengan deviasi lateral jempol kaki dan deviasi medial tulang metatarsal. Pada kasus ini perempuan lebih berisiko mengalami Hallux valgus (Bunion) dari pada laki-laki dengan perbandingan rasio 9:1. (4)

Hallux valgus pada tahap awal jarang muncul gejala (intermiten) dan tidak menyebabkan keterbatasan. ROM berkurang pada tulang Metatarsophalanx pertama, tetapi mungkin hanya satu arah. Kemudian pada stadium lanjut gejala menjadi lebih konstan dengan semakin sulitnya gerakan fleksi dan ekstensi, secara progresif akan menjadi ankilosis sendi disertai timbulnya inflamasi disertai bursitis sehingga menimbulkan nyeri pada sendi metatarsophalanx pertama ${ }^{(5)}$.

Hallux Valgus (Bunion) sebagian besar akibat genetik dan terdiri dari otot, ligamen, dan struktur pendukung metatarsal. Ini adalah suatu anomoli bio-mekanis yang dapat disebabkan oleh berbagai kondisi instrinsik struktur kaki seperti kaki datar, fleksibilitas berlebihan ligamen, struktur tulang tidak normal, dan kondisi neurologis tertentu. Hallux Valgus (Bunion) adalah jenis umum dari cacat yang terjadi ketika otot-otot melemah dan ligamen memegang tulang metatarsal pertama di pergeseran tempat jauh dari jari kaki lain. Pada saat yang sama, jempol kaki tergelincir ke dalam dan menyebabkan kelainan bentuk sudut (6).

\subsection{Metode dan Teknik Intervensi}

\subsubsection{Neuromuskular Taping (NMT)}

Neuro Muscular Taping (NMT) adalah aplikasi spesifik dari pita perekat elastis ke permukaan kulit dengan teknik stimulasi eksentrik menghasilkan dekompresi dan dilatasi pada daerah yang tertutupi yang digunakan untuk tujuan terapeutik. Dalam rehabilitasi, Neuro Muscular Taping (NMT) diterapkan menggunakan protokol yang dirancang untuk mengurangi sumbatan dari cairan tubuh, meningkatkan sirkulasi pembuluh darah dan kelenjar getah, menurunkan kelebihan panas, dan memperbaiki homoestasis jaringan, mengurangi peradangan dan hipersensitivitas reseptor nyeri. (7) 


\section{a. Teknik Pelaksanaan}

Pengaplikasian Neuro Muscular Taping (NMT) dengan teknik decompression akan membentuk lipatan-lipatan pada kulit. Sehingga memberikan efek yang dapat meredakan rasa nyeri, menormalkan ketegangan otot, meningkatkan sirkulasi darah dengan memperbesar ruang intestinal dalam jaringan dengan lipatan-lipatan dari efek decompression. Dengan adanya penurunan nyeri, dan menormalkan tegangan otot tersebut maka, akan meningkatkan kemampuan fungsional pada daerah penerapan. ${ }^{(8)}$

Potong taping dengan panjang 20-25 $\mathrm{cm}$, dengan metode I shaped cut menjadi 5 potongan dengan lebar $1 \mathrm{~cm}$.Pemasangan taping diaplikasikan 1 ditengah hallux,tape 2 disamping hallux kearah medial (posisi ekstensi phalanx).tape 3 (posisi kaki dorsofleksi) deviasi fleksi,kemudian tape 4 pada medial (abductor hallucis) kearah malleolus medial. ${ }^{(9)}$

\section{b. Mekanisme Penurunan Nyeri Pada Hallux Valgus}

Penerapan NMT mampu merangsang mechanoceptors kulit. Reseptor ini mengaktifkan impuls saraf ketika beban mekanik (sentuhan, tekanan, getaran, peregangan dan gatal) membuat deformasi. Aktivasi oleh stimulus yang memadai menyebabkan depolarisasi lokal, yang memicu impuls saraf di sepanjang serabut aferen bepergian ke sistem saraf pusat. Efek terapeutik NMT dengan menggunakan rangsangan decompressive untuk mendapatkan efek positif dalam muskuloskeletal, pembuluh darah, limfatik dan sistem saraf, meningkatkan sirkulasi darah, dan menghilangkan rasa sakit. Aplikasi yang benar juga dapat membantu untuk memperbaiki keselarasan sendi, otot, dukungan selama gerakan, dan meningkatkan stabilitas dan postur tubuh. (10)

\subsubsection{Strengthening Exercise}

Strengthening Exercise adalah gerakan tubuh, postur, atau aktivitas fisik yang dilakukan secara sistematis dan terencana guna memberi manfaat bagi pasien untuk memperbaiki atau mencegah gangguan, meningkatkan dan mengembalikan, atau menambah fungsi fisik, mencegah atau mengurangi faktor resiko terkait kesehatan, dan mengoptimalkan kondisi kesehatan, kebugaran, atau rasa sejahtera secara keseluruhan. (11)

Jenis latihan yang diberikan ada 3 antara lain Short-foot exercise,Toe-spread out exercise dan Heel-Raise Exercise.

a. Short-Foot Exercise

Short-foot atau biasa disebut toe grasp exercise merupakan program latihan untuk memperbaiki morfologi pada arkus longitudinal medial dengan mengaktifkan otot-otot instrinsik pada kaki.latihan ini dilakukan dengan cara memperpendek kaki yaitu membawa jari-jari kearah tumit tanpa adanya gerakan fleksi kaki atau seperti mencengkeram. (12)

b. Toe-Spread-Out Exercise

Latihan ini sangat direkomendasikan pada kasus hallus valgus,latihan ini terbagi kepada tiga gerakan jari kaki,semua latihan yang dilakukan menetapkan tumit pada lantai dengan cara mengangkat dan melebarkan jari-jari,kemudian dorong sedikit jari kelingking lebih keluar dari bagian tubuh dan lakukan gerakan mengulang sampai 10 kali,istirahat lalu ulang sampai 10-15 menit,penelitian ini menunjukkan hasil efektif untuk koreksi hallux valgus. (13)

c. Heel-Raise

ExerciseHeel-raise merupakan program latihan penguatan otot kaki dengan mengangkat tumit pada posisi berdiri atau dengan kata lain dalam keadaan berjinjit.pada saat berjinjit os.calcaneus dalam posisi vertical,tegak lurus dengan caput metatarsal 
yang horizontal.metatarsal tetap berada sejajar dengan lantai,karena memiliki fungsi untuk menopang berat tubuh.

\section{c. Mekanisme Strengthening Exercise dalam Mengurangi Nyeri}

Latihan strengthening exercise akan meningkatkan sirkulasi peredaran darah sehingga metabolism meningkat dan terjadi peningkatan difusi cairan sendi melalui matriks tulang.pemenuhan kebutuhan nutrisi tulang rawan sangat tergantung pada kondisi cairan sendi,maka suplai nutrisi untuk tulang rawan sangat tergantung pada kondisi cairan sendi,maka suplai nutrisi untuk tulang rawan menjadi adekuat.adanya kontraksi m.abductor hallucis dan otot-otot sekitar metatarsophalangeal pertama menjadi kuat karena mempermudah adanya mekanisme pumping action sehingga proses metabolism dan sirkulasi local dapat berlangsung dengan baik karena vasodilatasi dan relaksasi setelah terjadi kontraksi maksimal otot tersebut. (14)

\section{Hasil Studi Akhir}

Pada studi literatur kasus ini dapat dilihat dari penelitian Ekwere et al. yang berjudul "Pravelence of Hallux Valgus among Medical Student of The University of Jos" tahun 2016 yang ditunjukkan pada Tabel 1. dimana Tabel 1 menunjukkan prevalensi keseluruhan deformitas Hallux Valgus yaitu 16\% dari total populasi dengan prevalensi lebih tinggi pada wanita dibandingkan pria.

Tabel 1: Prevalence Of Hallux Valgus Deformity

\begin{tabular}{cccc}
\hline Sex & $\mathrm{N}$ & $\begin{array}{c}\text { Number of } \\
\text { subjects with } \\
\text { HV deformity }\end{array}$ & Prevalence \% \\
\hline Female & 100 & 11 & 11 \\
Male & 100 & 5 & 5 \\
Total & 200 & 16 & 16 \\
\hline $\mathrm{n}=$ Number, HV & Hallux Valgus
\end{tabular}

Penelitian ekwere didukung pada penelitian Bayar et al yang berjudul "The
Effects of NeuroMuscular Taping and Foot Exercise on Patient with Hallux Valgus" tahun 2011. Dimana wanita lebih cenderung terkena Hallux Valgus dari pada pria. Pada penelitian Bayar et al 2011. dilakukan pemanfaatan strengthening exercise dengan Neuromuscular taping untuk penanganan kasus Hallux Valgus, dimana intervensi tersebut dapat menurunkan derajat sudut hallux valgus, penurunan nyeri, dan peningkatan kemampuan berjalan. Subjek dalam penelitian ini dibagi menjadi dua Grup. Grup A dengan Strengthening exercise dan penggunaan NeuroMuscular taping dan Grup B hanya dengan Strengthening exercise.

Selanjutnya pada penelitian Jeon et al dalam Karabicak et al yang berjudul "Shortthem effect NeuroMuscular Taping on pain and joint alignment in conservative treatment of hallux valgus" tahun 2015. dilakukan penelitian Hallux valgus dengan intervensi NeuroMuscular Taping disertai Strengthening Exercise pada 50 responden, Hasil penelitian ditunjukkan pada tabel 4.

Tabel 4. Main results of the study

\begin{tabular}{|c|c|c|c|c|c|c|c|}
\hline & $\begin{array}{c}\begin{array}{c}\text { Before } \\
\text { treatment, } \\
\underline{\mathrm{n}=35} \\
\mathrm{X} \pm \mathrm{SD}\end{array}\end{array}$ & $\begin{array}{c}\begin{array}{c}\text { Innitial } \\
\text { effect, }\end{array} \\
\frac{\mathrm{n}=35}{\mathrm{X} \pm} \\
\mathrm{SD}\end{array}$ & $\begin{array}{c}\text { Day } \\
3, \\
\underline{\mathrm{n}=} \\
\underline{35} \\
\mathrm{X} \pm \\
\mathrm{SD}\end{array}$ & $\begin{array}{c}\text { Day } \\
7, \\
\underline{\mathrm{n}=} \\
\underline{34} \\
\mathrm{X} \pm \\
\mathrm{SD}\end{array}$ & $\begin{array}{l}\text { Day } \\
10, \\
\frac{\mathrm{n}=}{34} \\
\frac{\mathrm{X} \pm}{\mathrm{X}} \\
\mathrm{SD}\end{array}$ & $\begin{array}{l}\text { Day } \\
30, \\
\frac{\mathrm{n}=}{31} \\
\frac{\mathrm{X} \pm}{\mathrm{SD}}\end{array}$ & $\mathrm{P}$ \\
\hline $\begin{array}{l}\text { Adduction } \\
\text { angle }\end{array}$ & $\begin{array}{c}20,2 \pm \\
4,7\end{array}$ & $\begin{array}{c}16,3 \pm \\
5,2\end{array}$ & $\begin{array}{r}13,8 \\
\pm 3,8\end{array}$ & $\begin{array}{r}12,3 \\
\pm 4,3\end{array}$ & $\begin{array}{c}13,2 \\
\pm \\
4,9\end{array}$ & $\begin{array}{c}14,3 \\
\pm \\
5,0\end{array}$ & $\begin{array}{c}\mathrm{a}, \\
\mathrm{b}, \mathrm{c}\end{array}$ \\
\hline $\begin{array}{l}\text { VAS } \\
(\mathrm{Cm})\end{array}$ & $\begin{array}{c}7,45 \pm \\
1,5\end{array}$ & $\begin{array}{c}2,7 \pm \\
2,7\end{array}$ & $2,2 \pm$ & $\begin{array}{c}1,7 \pm \\
2,1\end{array}$ & $\begin{array}{c}1,2 \\
\pm \\
1,8\end{array}$ & $\begin{array}{c}1,1 \\
\pm \\
1,7\end{array}$ & $\begin{array}{l}\mathrm{a}, \mathrm{b}, \\
\mathrm{c}, \mathrm{f}\end{array}$ \\
\hline AOVAS & $\begin{array}{c}42,8 \pm \\
19,5\end{array}$ & - & $\begin{array}{c}73,1 \\
\pm\end{array}$ & $\begin{array}{r}75,0 \\
\pm 8,3\end{array}$ & $\begin{array}{c}76,7 \\
\pm \\
8,4\end{array}$ & $\begin{array}{c}76,7 \\
\pm \\
8,4\end{array}$ & A \\
\hline $\begin{array}{c}\text { FFI }(\mathrm{Cm}) \\
\text { Total }\end{array}$ & $3,2 \pm 1,6$ & - & $1,6 \pm$ & $\begin{array}{c}1,0 \pm \\
1,1\end{array}$ & $\begin{array}{c}0,76 \\
\pm \\
1,2\end{array}$ & $\begin{array}{c}0,84 \\
\pm \\
1,24\end{array}$ & $\begin{array}{l}\mathrm{a}, \mathrm{b} \\
\mathrm{c}, \mathrm{d}\end{array}$ \\
\hline Pain & $4,4 \pm 2,1$ & - & $2,0 \pm$ & $\begin{array}{c}1,4 \pm \\
1,7\end{array}$ & $\begin{array}{c}1,0 \\
\pm \\
1,5\end{array}$ & $\begin{array}{c}1,19 \\
\pm \\
1,44\end{array}$ & $\begin{array}{l}\mathrm{a}, \mathrm{b}, \\
\mathrm{c}, \mathrm{f}\end{array}$ \\
\hline $\begin{array}{l}\text { Quality of } \\
\text { life }\end{array}$ & $1,3 \pm 1,7$ & - & $\begin{array}{c}0,72 \\
\pm\end{array}$ & $\begin{array}{c}0,28 \\
\pm \\
0,74\end{array}$ & $\begin{array}{c}0,18 \\
\pm \\
0,53\end{array}$ & $\begin{array}{c}1,03 \\
\pm \\
1,23\end{array}$ & $\mathrm{a}, \mathrm{c}$ \\
\hline
\end{tabular}


Function $\quad 4,0 \pm 2,5 \quad-\quad 2,0 \pm \quad 1,2 \pm \quad 0,98 \quad 0,77 \quad \mathrm{a}, \mathrm{b}$, bulan, perbedaan jumlah hallux valgus dan $\pm \quad \pm \quad c, d$, sudut intermetatarsal masih tidak signifikan,

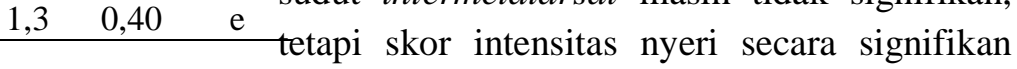

AOFAS, American Orthopaedic Foot and Ankle Society; FFI, Foot Function Index; SD, standard deviation; VAS, visual analogue scale.

$\mathrm{aPb}<005$ significant difference according to initial assessment.

b, c, d, e, fPb $<005$ significant difference between $3,7,10$, and 30 days.

Penelitian selanjutnya adalah penelitian Tehraninasr et al yang berjudul "Effect Treatment with insole on patients with painful hallux valgus" tahun 2008. dengan metode yang sama tetapi dengan penambahan insole atau brace mendapatkan hasil pada table 5. 30 responden wanita yang mengalami hallux valgus mengambil bagian dalam penelitian ini. Mereka dialokasikan secara acak di kelompok pertama atau kedua, dimana kelompok pertama dengan perawatan Strengthening Exercise dan NeuroMuscular Taping sedangkan kelompok kedua dengan NeuroMuscular Taping dan Insole atau brace.

Tabel 5. data comparison of the study variables before and after 3-month study

\begin{tabular}{|c|c|c|c|c|}
\hline \multirow[b]{2}{*}{ Variable } & $\begin{array}{l}\text { First } \\
\text { group }\end{array}$ & \multicolumn{3}{|c|}{$\begin{array}{r}\text { Secon } \\
\mathrm{d} \\
\text { group }\end{array}$} \\
\hline & $\begin{array}{c}\text { Befor } \\
\mathrm{e}\end{array}$ & After & Before & After \\
\hline $\begin{array}{l}\text { Pain intensity } \\
\text { score }\end{array}$ & $\begin{array}{c}4,26 \\
\pm \\
1,48\end{array}$ & $\begin{array}{c}2,66 \\
\pm \\
1,34\end{array}$ & $\begin{array}{c}4,13 \pm \\
1,78\end{array}$ & $\begin{array}{c}4,00 \\
\pm \\
1,13\end{array}$ \\
\hline Hallux & 25,46 & 25,3 & 24,13 & 24,1 \\
\hline Valgus angle & $\pm 3,68$ & $\begin{array}{c}6 \pm \\
3,68\end{array}$ & $\pm 2,05$ & $\begin{array}{c}6 \pm \\
2,09\end{array}$ \\
\hline Intermetatarsa & 13,56 & 13,4 & 12,46 & 12,4 \\
\hline 1 angle & $\pm 2,00$ & $\begin{array}{c}3 \pm \\
1,99\end{array}$ & $\pm 1,12$ & $\begin{array}{c}3 \pm \\
1,16\end{array}$ \\
\hline
\end{tabular}

Sebelum intervensi dilakukan, tidak ada perbedaan yang signifikan secara statistik dalam jumlah hallux valgus dan sudut intermetatarsal dan juga skor intensitas nyeri antara dua kelompok. Setelah penelitian 3 berbeda $(\mathrm{p}<0,05)$.

\subsection{Penurunan nyeri pada kasus Hallux Valgus dengan intervensi Strengthening Exercise dan NeuroMuscular Taping.}

Hallux Valgus atau Bunion merupakan deformitas pada ibu jari dengan kondisi Metatarsal mengalami deviasi ke arah medial dan ibu jari mengalami deviasi ke lateral dengan rotasi, kondisi tersebut disertai dengan atau tanpa adanya pelebaran ke arah medial dari jaringan lunak pada bagian distal metatarsal (Noor, 2016). Keadaan ini dapat mengakibatkan nyeri pada kaki dan kesulitan saat menggunakan sepatu yang berdampak pada kegiatan seharihari seperti berjalan, berlari dan bekerja, mengganggu mobilitas, meningkatkan risiko jatuh dan keseimbangan (Okuda et al, 2014).

Pada kondisi Hallux Valgus aksi Neuromuscular taping adalah menstimulus kutaneus, otot, reseptor pada sendi metatarsophalangeal pertama dan mengontrol nyeri dengan metode dekompresive yang menghasilkan wrinkle yang diaktifasi melalui Gerakan, wrinkle ini akan menyebabkan terangkatnya kulit sehingga memberikan ruang antara kulit dan jaringan dibawahnya, Neuromuscular taping akan menstimulus permukaan kulit dengan cara mengaktifasi mekanoreseptor yang berada dipermukaan kulit, dengan menggunakan gerbang control akan melewati serabut saraf berdiameter besar (A beta) dan kecil (A delta dan C) serabut-serabut nantinya akan berkumpul di tingkat substansi agalatinosa dari medulla spinalis. Apabila stimulus nyeri dan stimulus mekanik yang dihasilkan oleh Neuromuscular taping ditransmisikan secara bersamaan, transmisi stimulus nyeri akan di inhibisi akibat dari tindakan rangsangan yang diberikan serabut $\mathrm{A}$ 
beta pada neuron inhibisi di substansi agelatinosa (Blow, 2015).

Dengan perawatan menggunakan NeuroMuscular taping disertai dengan pemanfaatan latihan berupa Strengtening exercise secara simultan. Pendekatan ini mungkin dianggap sebagai pendekatan konservatif yang efektif untuk pasien dengan hallux valgus. Strengthening exercise akan meningkatkan sirkulasi peredaran darah sehingga metabolisme meningkat dan terjadi peningkatan difusi cairan sendi melalui matriks tulang. Pemenuhan kebutuhan nutrisi tulang rawan sangat tergantung pada kondisi cairan sendi, maka suplai nutrisi untuk tulang rawan menjadi adekuat. Adanya kontraksi $m$. Adductor Hallucis dan otot-otot sekitar Metatarsophalangeal pertama yang kuat akibat Strengthening Exercise akan mempermudah mekanisme pumping action (memompa kembali cairan untuk bersirkulasi) sehingga proses metabolisme dan sirkulasi lokal dapat berlangsung dengan baik karena vasodilatasi dan relaksasi setelah kontraksi maksimal otot tersebut, dengan demikian maka pengangkutan sisa-sisa metabolisme (Substansi $P$ ) dan asetabolic yang diproduksi melalui proses inflamasi dapat berjalan lancar sehingga rasa nyeri dapat berkurang (Afiani, 2015).

Dari ketiga penelitian yang dilakukan oleh Bayar et al 2011, Jeon et al dalam Karabicak et al 2015 dan Tehraninasr et al 2008 dengan intervensi penggunaan NeuroMuscular Taping dan Strengthening exercise yang sama dengan perbedaan dalam metode pengaplikasian menunjukkan hasil yang cukup signifikan dalam penurunan derajat nyeri

\section{REFERENSI}

[1]. Dorland, WAN. 2014. Kamus Saku Kedokteran Dorland Edisi 28. Jakarta: EGC

[2]. Fitria, A. 2015. Bunion. France: Lyon France. Pp 1-5.
[3]. Dewi. KAT. 2014. Studi Deskriptif: Prevalensi dan Distribusi Keluhan Muskuloskeletal pada Guru SD Pengguna Sepatu Berhak Tinggi di Kecamatan Klungkung. E-Jurnal Medika Udayana,ISSN 2303-1395

[4]. Radwan, Nadya Lotfy., Mohammed, Mervat Abdelrahman., Ibrahim, Abeer Ramadan., 2017. Conventional Tape versus Kinesiotape for Hallux Valgus Correction. International Journal of Medical Research and Health Sciences. 6 (1): 71-78

[5]. Macnab, M., Rome., Keith. 2015. Management of Chronic Musculoskeletal Condition in the Foot and Lower Leg. Cina: Elsevier Health Science.

[6]. Perera, A. M. 2011. Current Concept Review the Phatogenesis of Hallux Valgus. J Bone Joint Surg Am: 93 (1650).

[7,8]. Blow, D. 2013. NeuroMuscular Taping. New York: Edi Ermes.

$[9,10]$. Blow, D. 2015. Neuro Muscular

Taping Professional Training Courses Upper and Lower Extremity. WorkBook: NMT Institute

[11]. Kisner C. 2017. Terapi Latihan Dasar Dan Teknik. Jakarta: EGC.

[12]. Sulowska, I., Oleksy, L. \& Mika, A., 2016. The influence of short foot muscle exercise on foot posture and fundamental movement patterns in long-distance runners, a Non randomized, non-blinded clinical trial. Plos one, pp. 1-12.

[13]. Kima, MH., Kwonb, YH., Kimb, SH., Jungd, DY., 2013. Comprarison of muscle activities of abductor hallucis and adductor hallucis between the short foot and toe-spread-out exercise in subjects with mild hallux valgus. J Back Musculoskelet Rehabil. Pp. 26:163-168

[14]. Arnsdorff, K., Limbigh, K. \& Riemann, B.L., 2011. Analysis of heel raise exercise 
Jurnal Ilmiah Fisioterapi (JIF) Volume 4 Nomor 01 Februari 2021

with Three Foot positions. International journal of exercise sciene, pp. 13-21 